\title{
Study on Knowledge Level of Livestock Owners Related to Breeding Aspect of Organic Animal Husbandry Practices in Arid Region of Rajasthan
}

\author{
Gujar $B^{1}$, Purohit NR ${ }^{1}$ and Basant Bais ${ }^{* 1}$
}

${ }^{1}$ Department of Livestock Products Technology, CVAS, Rajasthan University of Veterinary and Animal Sciences, Bikaner, India

Received: 2 October, 2016; Accepted: 11 April, 2017; Published: 21 April, 2017

*Corresponding author: Basant Bais, Professor and Head, Department of Livestock Products Technology, CVAS, Rajasthan University of Veterinary and Animal Sciences, Bikaner, India; E-mail: basantbais@gmail.com

\begin{abstract}
A study was conducted in two selected districts of arid region of Rajasthan i.e. Barmer and Bikaner. From each selected district, two tehsils were selected purposively. She and Chohtan tehsils from Barmer district and Kolayat and Lunkaransar tehsils from Bikaner district were selected on the basis of highest livestock population and two villages were selected randomly from each tehsil. Thus, total eight villages were selected and from each selected village, 15 respondents were selected randomly making the sample size of 120 livestock owners in present study. Data were collected from livestock owners with the help of semi-structured interview schedule, researcher's own observations were also recorded regarding the breeding practices followed by livestock owners. From the study it was found that majority (40.8\%) of the livestock owners had high level of knowledge followed by medium $(32.5 \%)$ and low $(26.7 \%)$ level knowledge about breeding aspect of Organic Animal Husbandry practices. The sub-areas under different organic breeding practices in which the livestock owners had highest knowledge was promoted animals for natural service and knowledge of heat detection (mean score 1.00 for each) from breeding practices and the livestock owners had highest adoption about traditional methods for heat detection (adoption index 99.58). It was concluded that Livestock owners in Arid Region of Rajasthan mostly kept desi (local) breeds and preferred natural service for reproduction. These practices of farmers were well fitted with the standards of organic livestock farming related to breeding aspect.
\end{abstract}

practices

Keywords: Livestock; Breeding; Organic animal husbandry

\section{Introduction}

Livestock plays an important role in relation to the general principles of organic agriculture, supporting biological cycles within the farming system and diversifying production [1]. The situation for organic livestock farming had however changed radically during the past decade even though organic livestock production faces major challenges with regard to harmonization and successful integration of organic animal husbandry into the whole organic production system [2]. Livestock farming is an important part of organic farming systems both as a part of the concept and in practice, forming an integrated system with harmony among the land, the animals and the people. Organic farming starts at the bottom of the food chain by raising healthy soil, which grows healthy plants, which grow healthy animals, which make healthy human.

Knowledge is pre-requisite to the adoption of an innovation. The final decision of livestock owners to use a new practice is usually the result of their knowledge of the practice and attitude. Knowledge level of livestock owners refers to the information they possess in respect of organic animal husbandry practices. Knowledge of organic animal husbandry practices would lead to adoption or rejection. Once acquired and accumulated, knowledge produces change in the thinking process. The result of this is seen in behavioral change of the farmers. i.e; adoption about organic animal husbandry practices. Therefore, an effort has been made to ascertain the knowledge level possessed by the livestock owners regarding breeding aspect of organic animal husbandry practices.

\section{Materials and Methods}

The study was conducted in Barmer and Bikaner district of Rajasthan. These districts were selected purposively because most of the arid part of western Rajasthan as well as the major part of the livestock population of western Rajasthan are covered by these two districts. From each selected district, two tehsils were selected purposively. Sheo and Chohtan tehsils from Barmer district and Kolayat and Lunkaransar tehsils from Bikaner district were selected on the basis of highest livestock population and two villages were selected randomly from each tehsil. Thus, total eight villages were selected and from each selected village, 15 respondents were selected randomly making the sample size of 120 livestock owners in present study.

Knowledge for this study has been operationalized as, the extent of known information by the non organic farmers with regarding organic animal husbandry standards formulated by Government of India [3]. The knowledge of farmers was measured by developing 'tailor-made' test, based on the organic animal husbandry standards, covering breeding aspect of organic animal husbandry practices. 
The knowledge was measured on three-point continuum scale i.e. correct, partially correct and incorrect answer. The weight age of 2,1 and 0 was allotted to each correct, partially correct and incorrect answer, respectively. The knowledge score of each area viz. breeding, feeding, health care and management of a respondent was added up to know the level of knowledge in a particular area so as to prioritize the areas according to knowledge mean score obtained.

\section{Results and Discussion}

Knowledge level of livestock owners regarding breeding practices is presented in (Table 1).

Table 1: Knowledge level of livestock owners in different sub areas of breeding practices of $\mathrm{OAH}$ :

\begin{tabular}{|c|c|c|c|}
\hline S. No & $\begin{array}{l}\text { Sub areas of breeding } \\
\text { practices }\end{array}$ & $\begin{array}{l}\text { Mean } \\
\text { score }\end{array}$ & Rank order \\
\hline 1 & Best breed of animals for $\mathrm{OAH}$ & 0.99 & II \\
\hline 2 & $\begin{array}{c}\text { Advantages of local/desi } \\
\text { breeds }\end{array}$ & 0.70 & IV \\
\hline 3 & Best breeding techniques & 0.43 & $\mathrm{~V}$ \\
\hline 4 & $\begin{array}{c}\text { Hormonal treatment for heat } \\
\text { synchronization }\end{array}$ & 0.99 & II \\
\hline 5 & Knowledge of heat detection & 1.00 & I \\
\hline 6 & Heat symptoms in animals & 0.83 & III \\
\hline 7 & $\begin{array}{l}\text { Animals promoted for natural } \\
\text { service }\end{array}$ & 1.00 & I \\
\hline
\end{tabular}

The maximum obtainable score in each sub-area was 1.00 and therefore, all the sub-areas were scored out of a maximum total obtainable score of 1.00. The data presented in Table 1 showed that the area in which the knowledge level of livestock owners was found collectively highest and ranked first were animals promoted for natural service and knowledge of heat detection (mean score 1.00 for each) followed by knowledge of best breed of animals in organic animal husbandry and knowledge of Hormonal treatment for heat synchronization of animals (mean score 0.99 for each), The knowledge of heat symptoms in animals (0.83) and advantages of local /desi breed in organic animal husbandry (0.70) as overall third, fourth and fifth rank respectively. The lowest knowledge was found in best breeding techniques in organic animal husbandry (mean score 0.43 ).

The data presented in Table 2 revealed that majority (40.8\%) of the livestock owners had high level of knowledge followed by medium $(32.5 \%)$ and low (26.7\%) level knowledge about breeding aspects of organic animal husbandry practices.
Table 2: Distribution of livestock owners according to their knowledge level of breeding management practices of $\mathrm{OAH}$

\begin{tabular}{|c|c|c|c|c|}
\hline S. No & $\begin{array}{c}\text { OAH } \\
\text { Practices }\end{array}$ & $\begin{array}{l}\text { Knowledge level of } \\
\text { livestock owners }\end{array}$ & Frequency & $\begin{array}{l}\text { Percent } \\
(\%)\end{array}$ \\
\hline \multirow[b]{3}{*}{1.} & \multirow[b]{3}{*}{ Breeding } & Low $(<12.93)$ & 32 & 26.7 \\
\hline & & $\begin{array}{c}\text { Medium (12.93- } \\
14.47)\end{array}$ & 39 & 32.5 \\
\hline & & $\operatorname{High}(>16.01)$ & 49 & 40.8 \\
\hline
\end{tabular}

Adoption index for different subarea of breeding practices

The data presented in Table 3 showed that highest adoption was found for traditional method used for heat detection with adoption index 99.58 and ranked first. However, refusal of hormonal treatment for heat synchronization, native (desi) breed and using natural reproduction techniques having adoption index of 97.5, 92.5 and 53.61 and were ranked second, third and fourth, respectively. Low level of adoption related to breeding practices was observed in procurement of animals and sources of male animals which were having adoption index 38.05 and 20.27 respectively.

The data of present study are in accordance with Subrahmanyeswari and Chander and Nalubwama, et al who observed that natural mating was the most common method of breeding in cattle, goats and pigs in their organic study $[4,5]$.

\begin{tabular}{|c|c|c|c|}
\hline S. No & $\begin{array}{c}\text { Sub areas of breeding } \\
\text { practices }\end{array}$ & $\begin{array}{l}\text { Adoption } \\
\text { Index }\end{array}$ & $\begin{array}{l}\text { Rank } \\
\text { Order }\end{array}$ \\
\hline 1 & Native(desi) breeds & 92.5 & III \\
\hline 2 & $\begin{array}{l}\text { Natural reproduction } \\
\text { techniques }\end{array}$ & 53.61 & IV \\
\hline 3 & Source of male animals & 20.27 & VI \\
\hline 4 & Type of male animals & 20.27 & VI \\
\hline 5 & Heat detection methods & 99.58 & I \\
\hline 6 & $\begin{array}{l}\text { Refusal of hormonal } \\
\text { treatment for heat } \\
\text { synchronization }\end{array}$ & 97.5 & II \\
\hline 7 & Procurement of animals & 38.05 & V \\
\hline
\end{tabular}


In organic livestock farming, a breed of different species of livestock is an important consideration. The livestock owners were asked about the breeds of different animals they possessed. The data presented in Table 3 showed that almost all the owners possessed native (desi) breeds of cattle, buffalo, sheep, goat and camel. The negligible number of livestock owners kept crossbred/exotic cattle. Less feed requirement, less care, more disease resistance, easy availability, could be the reasons for keeping desi breeds of different livestock.

From organic production point of view, this is a favorable situation as the standards for organic animal husbandry (IFOAM-India, 1996) has emphasized on the preservation of indigenous breeds and keeping of breeds which are adapted to local conditions. Breeding goal under organic management should be such that livestock diversity is maintained [6]. So, the cross breeding which is being promoted since 1950s in India, goes against the philosophy of organic production and the selective upgrading of the native breeds would be the choice for improving the productivity of livestock under the organic management of livestock.

The farmers were asked about the reproduction technique (natural service or A.I.) they follow in their farms. The results presented in Table 3, showed that majority (53.61) of livestock owners used natural service for animals [7]. Easy availability, no fees, no monitoring and high conception rate could be the reasons for adoption of natural service as compared to A.I.

\section{Conclusions}

From above study It was found that majority (40.8\%) of the livestock owners had high level of knowledge followed by medium (32.5\%) and low (26.7\%) level knowledge about breeding practices of OAH. The sub-areas under different organic breeding practices in which the livestock owners had highest knowledge was promoted animals for natural service and knowledge of heat detection (mean score 1.00 for each) from breeding practices. The sub-areas under different organic breeding practices in which the livestock owners had highest adoption were used traditional methods for heat detection (adoption index 99.58). It was observed that Livestock owners mostly kept desi (local) breeds and preferred natural service for reproduction. The source of breeding male was within the region. Only few farmers using modern breeding techniques. These practices of farmers were well fitted with the standards of organic livestock farming.

Thus, on basis of above findings, it may be concluded that in Arid Region of Rajasthan most of the livestock owners were following organic livestock management practices related to breeding aspect without much knowing the advantages of organic production system. All these practices conferred a high standard of animal welfare, most sought criteria for organic farms

\section{References}

1. Hermansen JE. Organic livestock production systems and appropriate development in relation to public expectation. Livest. Prod. Sci.2003;80(1-2):3-15.

2. Hovi M, Sundrum A, Thamsborg SM. Animal health and welfare in organic livestock production in Europe: current state and future chal- lenges. Livest. Prod. Sci. 2003;80(1-2):41-53.

3. NPOP. National programme for organic production containing the standards for organic products. Department of Commerce, Ministry of Commerce and Industry, Government of India. 2000.

4. Subrahmanyeswari B, Chander M. Compatibility of animal husbandry practices of registered organic farmers with organic animal husbandry standards (OAHS): an assessment in Uttarakhand. Indian J Anim Sci. 2008;78(3):322-327.

5. Nalubwama S, Vaarst M, Kabi F, Kiggundu M, Bagamba F, Odhong C, et al. Challenges and prospects of integrating livestock into smallholder organic pineapple production in Uganda. Livestock Research for Rural Development .2014;26(6).

6. IFOAM. Definition of Organic agriculture. Available at: http://www. ifoam.org/growingorganic/definitions/doa/index.html (Accessed March 10, 2013). 2014.

7. Noordhuizen J, Bonnefoy JM. Heat Stress in Dairy Cattle: Major Effects and Practical Management Measures for Prevention and Control. SOJ Vet Sci. 2015;1(1):1-7. 